\title{
Por uma história da noção de campo
}

\author{
Bertrand Pulman \\ Tradução: Wilma Marques Leitáo \\ Revisấo Técnica: Adriana de Oliveira Silva, Daniela do Amaral Alfonsi, \\ Jayne Hunger Collevatti e Luísa Valentini
}

\begin{abstract}
"Primeiramente, para além do racional existe uma categoria mais importante e mais fértil, a do significante, que é a mais elevada forma de ser do racional mas cujo nome nossos professores (decerto, mais ocupados em meditar sobre o 'Essai sur les données immédiates de la conscience' do que sobre o 'Curso de Lingüística Geral' de Saussure) nem sequer pronunciavam" (CLAUDE LÉVI-STRAUSS, 1996:53)
\end{abstract}

Todos os antropólogos, quaisquer que sejam suas opçóes teóricas, consideram que o que se convencionou denominar $\operatorname{campo}^{1}$ constitui uma das dimensóes essenciais do procedimento antropológico. Neste sentido, Lévi-Strauss afirma nitidamente que "o antropólogo necessita da experiência do campo" e aponta que

só o julgamento de membros experimentados da profissão, cuja obra atesta que eles próprios contornaram o cabo com sucesso, pode decidir se, e quando, o candidato à profissão antropológica terá realizado, no campo, esta revoluçáo interior que fará dele, verdadeiramente, um homem novo (1967, p. 416).

Em tom similar, Condominas declara que

1. N.T.: Levaremos em consideração que as citaçôes de Condominas, Malinowski e Jones, reproduzidas neste artigo, são traduções em francês de frases inicialmente pronunciadas ou redigidas em inglês. A mesma observação vale para as traduçóes de terrain em português: campo/terreno. o momento mais importante de nossa vida profissional ainda é o trabalho no campo; ao mesmo tempo nosso laboratório e nosso rito de passagem, o campo transforma cada um de nós num verdadeiro antropólogo (1972, p. 2).

Dessa forma, não espanta ver-se multiplicar palestras e publicaçóes referentes ao conceito de campo e suas representaçóes. Iniciada já há algum tempo nos Estados Unidos, desenvolve-se incontestavelmente hoje na França uma interrogação histórica, metodológica e epistemológica sobre campo. Os textos reunidos recentemente sobre esse assunto por iniciativa da Associação Francesa de Antropólogos (1987) são testemunhos desse movimento reflexivo, ao mesmo tempo necessário e inevitável: quando procuram definir melhor a especificidade, o estatuto ou as perspectivas de futuro de sua disciplina, os antropólogos são naturalmente levados a indagar o que recobre a noção de campo. Tal reflexão é, com toda certeza, legítima e útil.

Em sua grande maioria, os textos sobre campo produzidos por antropólogos têm valor de testemunho: desse ponto de vista, constituem preciosos documentos. Contudo, num plano estritamente teórico, esses textos suscitam muitas vezes dúvidas. De fato, por termos procurado "meditar" o máximo possível sobre o Curso de Lingüistica Geral (C.L.G.) de Saussure, parece-nos essencial apresentar a seguinte questão: não estarão baseados numa confusão entre o campo e o CAMPO a maior parte dos discursos dos antropólogos sobre o campo? 
$222 \mid$ Bertrand Pulman

Essa confusão entre o signo e seu referente é inelutável e relativamente inócua se um antropólogo diz, por exemplo, que se está preparando para "ir para campo". No entanto, encerra certo inconveniente se esse mesmo antropólogo diz que pretende "refletir sobre o campo". Pois, neste caso, o objeto de sua reflexão, ainda que sendo um conceito teórico-prático, não deixa de ser também um objeto conceitual. $\mathrm{O}$ fato de tal conceito remeter, aos olhos do antropólogo, para uma vivência do real é incontestável, mas não deve ocultar o cerne da descoberta saussuriana.

Sob o conceito de campo encontra-se uma imagem acústica /cãNpo/. É precisamente esta união de um significado e de um significante que dá a campo seu estatuto primeiro de signo, conforme o esquema bem conhecido, mas freqüentemente esquecido:

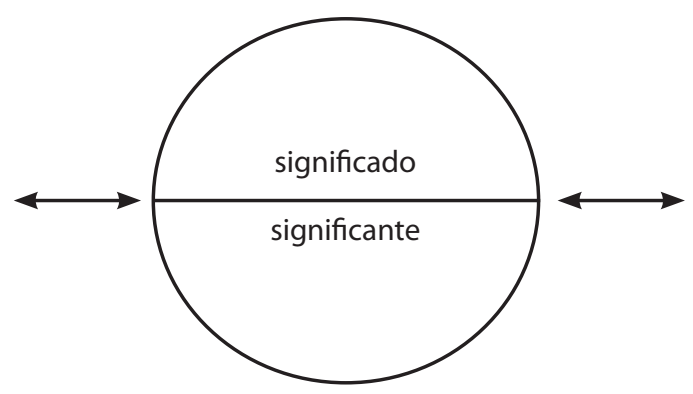

A língua, assim, associa de uma maneira indissolúvel, o pensamento e o som. Notemos que sobre isso o C.L.G. destaca:

A Lingüística trabalha, pois, no terreno limítrofe onde os elementos das duas ordens se combinam; esta combinação produz uma forma, não uma substância (Saussure, 1965, p.131)2.

O antropólogo poderia considerar que a definição do signo campo interessa apenas ao lingüista, isto se o C.L.G. náo nos ensinasse uma

2. Cf. sobre esta passagem Saussure, 1972, pp. 157 e 463. outra coisa fundamental: não sendo a língua uma nomenclatura, a relação de um signo com seu referente é, no mínimo, problemática!

Parece-nos, entấo, que uma reflexão sobre o campo deve partir da seguinte constataçáo: quando falam do campo, os antropólogos utilizam um signo que ocupa uma posição específica no sistema de signos constituído pela língua francesa. Quem leve a sério o C.L.G. não pode considerar que esta mediação incontornável da língua é sem importância. $\mathrm{O}$ campo não é nenhuma experiência transparente em sua própria eficácia, nenhum dado imediato da consciência. O campo é, antes de tudo, algo aquém de nossas frases. Daí que se deva indagar quais as conseqüências do fato de empregar o signo campo para referir-se a uma experiência que alguns locutores afirmam ter do mundo. O que nos propomos apresentar aqui, são as premissas de uma tal problematização do campo no nível da língua.

Trata-se assim de levar a questão do campo para o campo da língua ${ }^{3}$. Projeto que o autor está consciente de ser eminentemente perigoso, uma vez que o próprio Saussure alertou contra o fato de que

todo aquele que se coloca no campo da língua pode admitir ter sido abandonado por qualquer analogia do céu e da terra (1954, p. 64).

Se com isso todas as certezas vacilam, é primeiramente porque o signo é arbitrário. Arbitrário não na medida em que o conceito de campo náo estaria ligado por qualquer necessidade interna à imagem acústica que lhe

3. Na medida em que nos situamos no campo da língua deve ser entendido que nossas observaçôes sobre o campo não pretendem considerar a coisa em si. Trata-se aqui de examinar o campo enquanto signo e, além, disso, analisar algumas dificuldades que a definição do referente desse signo implica. 
serve de significante. É arbitrário, muito mais fundamentalmente, porque a organizaçáo formal dos significantes e dos significados independe dos caracteres intrínsecos da substância fônica e da substância significativa. Dito de outra forma, nada, na massa de significaçôes possíveis, predetermina a discriminaçáo que opera a língua francesa ao dotar-se do signo campo $o^{4}$.

A história da língua francesa pode, todavia, nos ajudar a decodificar o valor atual desse signo. Recorrer à história da língua surpreenderá apenas quem ainda náo tenha entendido que a prioridade metodológica dada ao ponto de vista sincrônico não exclui uma reflexão sobre o devir da língua, muito pelo contrário. Tornase, assim, exatamente a mesma coisa dizer que o signo é arbitrário, que a língua forma um sistema e que existe uma "historicidade radical

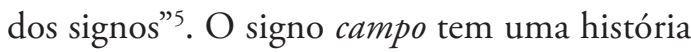
cuja etapa é importante retraçar para medir suas ressonâncias atuais.

Comecemos vendo o que pode nos ensinar um bom dicionário de língua francesa (ROBERT, 1965 e 1986). O signo terrain aparece na língua francesa no século XII. Constitui-se a partir do latim "terrenum", forma substantivada do adjetivo "terrenus" que significa "formado de terra”. Alguns gramáticos como Vaugelas e Richelet, aliás, tentaram no século XVII restituir uma ortografia "terrein" mais condizente com a origem etimológica do signo ${ }^{6}$. A princípio, a significação é unicamente telúrica: o signo terrain é utilizado para designar uma extensão de terra considerada em seu relevo ou em sua situaçáo. É por isso que falamos de um terreno plano, montanhoso, arborizado ou fértil; e é nesse mesmo sentido que se formam,

4. cf. Martinet, 1957 e os comentários de T. de Mauro, in Saussure, 1972, pp 420-422 e 442-445

5. Comentários de T. de Mauro, in Saussure, 1972, p.449

6. A ortografia "terrein" é, ainda, a preferida de Littré. hoje em dia, expressóes como "um veículo offroad".

No final do século XVII, o signo entra em um novo campo semântico, pois a arte militar se apropria dele. Nesse novo âmbito, o campo se associa ao campo de batalha: o signo campo designa o lugar onde se realizam as operaçôes militares e, num uso especializado, a arena onde se pratica um duelo. A instalação de fortificaçóes provisórias constitui a base de uma ciência de "organização do campo", ensinada nas Escolas Militares ${ }^{8}$. É a esta parte belicosa da história do signo campo que Breton se refere quando escreve:

sabemos com que orgulho tais especialistas das "ciências do homem" se prevalecem de sua estadia no campo, por menos perigoso e mais breve que seja, e em suas bocas esta locuçáo toma a mesma solenidade que na dos duelistas (1962, p.10).

Esta dimensão guerreira do campo/terreno é pano de fundo para uma série de expressōes que fazem parte da linguagem comum atual: disputar o terreno, ganhar ou perder terreno, conhecer o terreno, ter vantagem no campo, um campo de esporte etc. E foi nesse contexto militar que surgiu a expressáo "ir a campo" - que significa originalmente ir aos locais de combate -, antes de tomar por extensão o sentido figurado mais geral de "ir ao local", "lá onde acontece aquilo de que se fala". As conotaçôes belicosas da expressão permanecem, às vezes, bem explícitas. Por exemplo, em 1871, o jurista Émile Alglave escreveu na Revue Scientifique, de que era redator-chefe:

7. N.E: No original, em francês, o termo utilizado é vehicule pour tout que, na França, segundo a tradutora, é conhecido como veículo "utilitário". Entendemos, porém, que o termo que melhor representa essa idéia é off-road.

8. Cf. Corvisier, 1988, pp. 340-346

cadernos de campo, São Paulo, n. 16, p. 221-232, 2007 
só podemos almejar uma desforra tomando da Alemanha as armas que nos venceram. É, pois, no campo da ciência que deveremos combater primeiro, para nos prepararmos a lutar em outros campos de batalha, porque hoje somente a ciência dá a vitória? .

O campo é, ao mesmo tempo, uma extensão de terra e um lugar onde se desenrola algo que é da ordem do enfrentamento. Veremos, mais adiante, como o discurso antropológico joga simultaneamente com essas duas acepções.

Mas a história da utilizaçáo do signo campo no vocabulário científico não pertence propriamente à Antropologia: desde o final do século XVIII campo surgiu no discurso da Geologia, i.e., da ciência que estuda a história e a estrutura da parte externa do globo terrestre.

O signo terrain foi inicialmente utilizado por ocasião da tradução francesa dos trabalhos do mineralogista alemão Werner e do geólogo escocês Hutton. Designa, então, um conjunto de camadas sedimentárias acumuladas durante uma determinada época. Com isso, esse signo se encontra no cerne de um debate científico extremamente vivo, referente à origem das rochas que compóem a crosta terrestre. Este debate opóe os oceanos aos vulcóes. Werner, em seus cursos na Academia de Minas de Freiberg, sustenta a teoria dita “netuniana”, que atribui à ação da água o papel principal na formação das rochas; Hutton, em Theory of the Earth, with Proofs and Illustrations (1795), defende o "plutonismo", que destaca a ação do fogo interior do globo. A referência à idade e à origem dos terrenos é central: dir-se-á de um terreno que ele é primitivo, sedimentário, vulcânico, primário, secundário etc. Notemos imediatamente que esse questionamento histórico sobre terreno também implica considerar sua natureza e sua ordenação. Veremos adiante as incidências

9. Citado por Linda Clark em "Le darwinisme social en France” in: La Recherche, Fev. 1988:196. desta conjunção necessária entre uma reflexão sobre a história e uma reflexão sobre a estrutura dos terrenos.

No século XIX, o signo terrain estava firmemente implantado no vocabulário científico dos geólogos franceses. Brongniart publica "Tableau des terrains qui composent l'écorce du globe" (1829), Desnoyer estuda os terrenos da bacia do Sena (1929), Prévost descobre um "fóssil de pássaro de dimensóes gigantescas" explorando os "terrenos parisienses" (1855) etc.

Assim, antes de entrar no léxico dos antropólogos, o signo terrain possui uma longa história geológica e essa densidade histórica do signo não é indiferente.

O leitor certamente deve se lembrar que, em Tristes Trópicos, Lévi-Strauss elevou a Geologia à categoria de uma de suas "três mestras" (1996, p.56).

Esta referência à Geologia aparece numa passagem em que Lévi-Strauss explica como, nos anos trinta, a leitura de Freud o levou a distanciar-se um pouco das antinomias estáticas sobre as quais se construíam, naquela época, as dissertações filosóficas ${ }^{10}$. Sobre isto, escreve:

esta evolução intelectual, pela qual passei junto com outros homens de minha geração, coloriase, no entanto, de um matiz particular em virtude da intensa curiosidade que, desde a infância, me encaminhara para Geologia.

Mesmo antes do périplo brasileiro, a pesquisa realizada no planalto languedociano na busca da linha de contato entre duas camadas geológicas oferece, aos olhos de Lévi-Strauss, "a própria imagem do conhecimento". Pois o campo geológico constitui um lugar privilegiado para atingir "o sentido, augusto entre

10. Note-se que foi neste mesmo contexto que aparece a frase de Lévi-Strauss que apresentamos como epígrafe deste artigo. 
todos". E o momento em que surge este "sentido supremo" é onde "o espaço e o tempo se confundem” (1996, p.54).

$\mathrm{Na}$ realidade, o que o sentido geológico de terreno/campo exibe àquele que sabe apreendêlo além de sua aparente desordem, é a profunda coerência que liga toda a estrutura presente à sua história. Dito de outra forma, o sentido geológico de campo/terreno, por sua própria natureza, obriga o pesquisador a procurar a justa articulação entre o ponto de vista sincrônico e o ponto de vista diacrônico. E sobre isso, todos conhecem a contribuição considerável da obra de Lévi-Strauss no domínio da Antropologia. E todos sabem também o que é devido a Saussure, no domínio da Lingüística. Todavia, os pesquisadores das Ciências Sociais geralmente ignoram que o problema sincronia/diacronia fora colocado bem mais cedo na Geologia. Antes de sua história na Antropologia, e mesmo antes de sua proto-história na Linguística, o sentido dado, hoje, à palavra campo tem uma pré-história que se desenrolou na Geologia.

Um texto de Prévost, geólogo francês que se empenhou, particularmente, em estabelecer uma teoria explicativa da aparição das montanhas pela retraçáo progressiva da crosta terrestre, mostra que a própria definição do conceito de terrain se encontrava no cerne do problema sincronia/diacronia tal como havia sido posto na Geologia.

Em 1845, Prévost apresenta uma comunicação na Academia Real de Ciências, intitulada De la chronologie des terrains et du synchronisme des formations. Este trabalho está inteiramente dedicado a estabelecer a prioridade que deveria ter, no plano metodológico, o ponto de vista sincrônico na Geologia. Propóe inicialmente "fixar a nomenclatura geológica" referente ao estudo do solo (Prévost, 1845, p.1). Prévost sugere uma distinção bem precisa dos três pontos de vista segundo os quais o solo pode ser estudado: o geólogo falará de rochas, de formaçôes ou de terrenos, segundo esteja interpretando os materiais do solo em função de sua composição mineralógica (calcária, argilosa etc), das causas de sua elaboração (aquosa, ígnea etc) ou do período do tempo em que surgiram (primário, secundário etc) ${ }^{11}$.

Enquanto a organização da crosta terrestre era relacionada com uma origem causal única, tais distinções não se impunham. Werner, por exemplo, imputava a organização das substâncias que compóem o solo a um único determinismo aquoso: por esta razão, ele interpretava os depósitos superpostos unicamente em função de sua data de formação, privilegiando o ponto de vista diacrônico.

Porém, aos olhos de Prévost, os progressos da Geologia tinham revelado que causas diversas podiam ter atuado simultaneamente:

O estudo dos fenômenos atuais e sua aplicação à explicaçấo dos fenômenos antigos permitiram demonstrar, como uma verdade incontestável, a ação sincrônica desde os tempos mais remotos, das duas principais causas plutoniana e netuniana ${ }^{12}$.

Daí a necessidade inicial de distinguir claramente entre a contemporaneidade das formações e a sucessão dos terrenos, bem como de tirar disso as conseqüências referentes à utilização do método comparativo: "é preciso comparar os terrenos entre si, nas formaçóes de mesmo tipo"13.

A conclusão metodológica que se depreende dessa perspectiva é evidente e prefigura diretamente o princípio estabelecido por Saussure e Lévi-Strauss em seus respectivos domínios:

O sincronismo é, para o estudo do solo e da história da terra, um princípio fundamental que deve ser tomado em consideração inicial e

11. Ibidem, p. 02

12. Ibidem, p. 03.

13. Ibidem, p. 07. 
226 | Bertrand Pulman

seriamente, pois existe sincronismo nos fenômenos, nos acontecimentos e nos produtos; o sincronismo é encontrado nos grandes fatos, como nos menores detalhes ${ }^{14}$.

Ao final dessa breve incursão na profundeza histórica do signo, podemos retornar à questão de seu valor atual. Este problema enseja quatro consideraçôes de nossa parte:

- Hoje, nos discursos tanto de antropólogos como de geólogos, o signo terrain é usado para designar tanto o objeto da pesquisa quanto o lugar onde se desenrola fisicamente o primeiro ato da pesquisa.

Em Geologia, campo/terreno é, principalmente, um conjunto de sedimentos acumulados, constituindo determinada porção da crosta terrestre, da qual o pesquisador estuda a idade e a estrutura. O geólogo poderá dizer, por exemplo, que

a medida das velocidades de desintegraçáo dos elementos radioativos permite determinar a idade dos terrenos sedimentares (Birembaut, 1957, p.1124).

Mas campo é também o lugar onde se exerce uma parte da atividade de pesquisa geológica: o que é, entâo, para um geólogo o 'seu' campo? É o domínio geográfico, onde se observa diretamente, seja numa apresentação natural seja composta artificialmente, as rochas que ele quer estudar. Observar a face frontal de uma pedreira, escavar com a pá, fazer perfurações, seguir um afloramento por indícios superficiais, tudo isto é "trabalho de campo". Claro que o geólogo somente irá formular suas conclusóes definitivas depois de "muitas idas e vindas campo-laboratório" (Pomerol e Blondeau, 1968, pp. 13 e 61). Algumas obras de Geologia, aliás, condensam essas duas concepções intitulandose simplesmente Géologie de Terrain (Bates e Kirkaldy, 1977).

Sabe-se que em Antropologia, o signo se declina através da mesma bipolaridade semântica. Campo torna-se objeto, para quem diz, por exemplo, "meu campo é constituído pelos Nuer do Sudão meridional"; e é lugar quando se diz "semana que vem vou para o meu campo".

- Tanto para a Geologia quanto para a Antropologia, campo suscita o mesmo uso de adjetivos e pronomes possessivos.

As fraseologias contemporâneas, da Geologia e da Antropologia, parecem revelar que existe, em torno do campo, algo que é da ordem do íntimo, da identidade própria do locutor.

Como toda identidade, a que está em jogo neste tipo de enunciado se apresenta como eminentemente social, uma vez que se articula em torno do problema do reconhecimento pelos pares e da entrada numa comunidade científica. As citaçōes de Lévi-Strauss e Condominas, reproduzidas no início deste artigo, são explícitas nesse ponto. $\mathrm{Na}$ Geologia, esta dimensão comunitária se formula de maneira quase idêntica na medida em que, por exemplo, pronuncia-se: que "aquele que náo foi ao campo não pode arvorar-se em geólogo" 15 .

- Em Geologia como em Antropologia, a prática do campo é objeto de uma valorização que se sustenta num discurso negativo sobre o passado: os tempos incertos da Geologia e da Antropologia de varanda estariam longe.

De acordo com a mitologia antropológica, Malinowski teria iniciado essa renovação ao declarar:

O antropólogo deve renunciar a sua confortável espreguiçadeira da varanda de uma casa de missionário, de uma repartição governamental ou de um bangalô de fazendeiro onde, armado de 
papel e lápis, e tomando de vez em quando um gole de uísque com soda, entrevistava os informantes, gravava histórias e preenchia páginas e páginas com textos de folclore primitivo (1926, p.153).

Assim como nossos pobres predecessores dispunham apenas do lápis e do caderno para conduzir a termo seu "survey" superficial, devemos constatar que "no final do século XIX, o geólogo dispóe apenas do martelo e da lupa para trabalhar no campo" (Birembaut, 1957, p.1123).

Tanto num caso como em outro, campo vem a ser objeto de uma mesma valorização. Que esta valorização obedece às exigências dos procedimentos científicos, não há qualquer dúvida, mas esta constatação não impede de destacar que ela repousa numa encenação discursiva.

Consideremos, por exemplo, a tradução para o francês de uma passagem do texto de Malinowski sobre o mito na psicologia primitiva, em que o autor precisa seu objetivo:

Este objetivo consiste em convidar os leitores a se afastar dos trabalhos de gabinete, aos quais se dedicam os teóricos, para sair ao ar livre que se respira no campo de pesquisa antropológica e reviver comigo o sentimento dos anos que passei em uma tribo melanésia da Nova Guiné. Remando na lagoa, observando os nativos trabalhando em suas roças sob um sol ardente, seguindo-os pelas trilhas da floresta, pelas praias tortuosas e pelos rochedos, aprendemos a conhecer sua vida ${ }^{16}$.

Uma passagem como esta, além do estetismo literário a que recorre, tem como objetivo subterrâneo, sustentar a legitimidade do discurso científico. Nas entrelinhas, ele apresenta

16. Idem, p. 101 uma autoridade etnográfica que, antes mesmo de ser escrito o texto antropológico, garante que nele está a verdade. Inúmeros pesquisadores, sobretudo nos Estados Unidos, consagraram-se à arqueologia e à desconstruçáo deste tipo de encenação ${ }^{17}$. Este questionamento, que evidentemente não advoga por um retorno à armchair anthropology, pode se tornar frutífero na medida em que é suscetível de abrir o texto antropológico à existência de novos regimes discursivos possíveis.

$\mathrm{O}$ progresso que constituiu o estabelecimento da etnografia intensiva é incontestavelmente imenso. Mas é lamentável que a antropologia de campo seja constituída sobre a desvalorização dos trabalhos dos comparatistas do século XIX. De fato, esse movimento acarretou, ao mesmo tempo, numa desvalorização a priori do trabalho teórico, explícito na frase de Malinowski citada acima ${ }^{18}$. A sua maneira, Jones destacou este fato ao declarar, diante do Royal Anthropological Institute:

Atualmente, o pesquisador de campo tem uma vantagem inconteste sobre aqueles a quem, num orgulho impertinente, ele se refere, às vezes, como "antropólogos de varanda" (1924, p. $47)^{19}$.

17. Cf. por exemplo, Stocking, 1983; Clifford, 1998; Rabinow, 1986

18. Este posicionamento anti-teórico é, de certa forma, ainda mais nítido na crítica à "antropologia de poltrona", desenvolvida por Franz Boas nos Estados Unidos.

19. Esta passagem foi mal traduzida na ediçáo francesa da obra de Jones. O texto original é: "As a result the field-worker today has an unquestioned advantage over those to whom in overweening pride he sometimes refers as "armchair anthropologists" (in J.R.A.L., 1924, p.47). O tradutor traduziu "unquestioned" por "incontestável”, ao invés de "incontesté" (Tradução francesa, 1973, p.105). Considerando nosso objetivo neste artigo, o leitor deverá compreender que a diferença possui, aos nossos olhos, uma grande importância. 
- Em Geologia como em Antropologia, campo se apresenta, inicialmente, como uma categoria unicamente telúrica; designa um segmento da crosta terrestre ou, por extensão, a etnia que habita essa porção do globo. Porém, em consonância com a origem belicosa da expressão "ir para o campo", o campo é também, de maneira mais ou menos explícita, um lugar de confronto.

Em Geologia, este confronto ocorre de várias maneiras. Primeiramente, nosso planeta é percebido como receptáculo e produto de uma vida interna tumultuada, onde se confrontam as forças geodinâmicas das quais os terrains são, na superfície, ao mesmo tempo resultante e testemunho. Abaixo d'A Crosta da Terra (Allègre, 1983), a física do globo restitui a violência desses choques, cujas manifestaçóes mais perceptíveis são o vulcanismo, os sismos, a deriva dos continentes, a expansão dos solos oceânicos e a evolução dos isótopos radiogênicos ${ }^{20}$.

Mais radicalmente ainda, o campo geológico constitui um espaço onde se entrechocam os materiais brutos com os quais o pesquisador é confrontado e seu projeto científico:

Em todos os casos [Geologia, Psicanálise, Marxismo], coloca-se o mesmo problema, o da relação entre o sensível e o racional. E o objetivo buscado é o mesmo: uma espécie de super-racionalismo, visando a integrar o primeiro ao segundo sem nada sacrificar de suas propriedades (Lévi-Strauss, 1996, p. 55).

A constituição do saber assenta na possibilidade de transformar esse engavetamento entre o sensível e o racional numa sintese objetiva.

Da mesma forma, no discurso antropológico, campo se apresenta como o lugar de diversos confrontos: entre as diferentes forças que se chocam no interior de uma cultura que lhes dá

20. Cf. Hamelin e Dupré, 1988. sua configuração específica; mais radicalmente ainda, entre a documentaçáo etnográfica em estado bruto e as categoriais usuais de análise do pesquisador. Por esta razão, a prática da profissão antropológica está "repleta de perigos"21: perigos físicos, como as doenças, mas, sobretudo, perigos simbólicos, uma vez que o antropólogo deve passar pela provação do abandono de si mesmo, sem, contudo, perder seu projeto de conhecimento. Igualmente, para ir para o campo, o antropólogo aprendiz deve estar armado de uma formação adequada que lhe permitirá realizar, no campo, esta síntese tão desejada.

Há algum tempo, desenvolve-se uma reflexão sobre os mecanismos subjacentes à constituição do texto antropológico ${ }^{22}$. Parece-nos, pessoalmente, que uma das potencialidades presentes na escrita antropológica reside na possibilidade de inventar novas formas textuais, que permitiriam não ocultar esta dimensão belicosa da experiência do campo, sem, contudo, afundar nela totalmente. Desde a publicação de alguns diários e cadernos de campo de antropólogos, o leitor sabe que uma parte da verdade do campo se avizinha com a sexualidade e a morte; a reinscrição desta parte maldita, no próprio texto antropológico, apresenta-se hoje como uma necessidade. Com esta finalidade, provavelmente seria preciso meditar sobre a frase de Leiris:

A propósito do ato amoroso - ou melhor, da cama que é seu teatro - eu empregaria de bom grado a expressáo "campo de verdade" para o que, em tauromaquia, designa a "arena", i.e., "o lugar do combate” (1939, pp. 69-70).

Do ponto de vista da problematização de campo, no âmbito da linguagem, inúmeras outras pistas de pesquisa além das abordadas aqui poderiam ser seguidas. Desejaríamos, para

21. Idem, 1967, p. 416).

22. Cf. por exemplo, Clifford e Marcus, 1986. 
terminar, desdobrar algumas delas. As observaçôes que se seguem têm, pois, em nosso espírito, valor essencialmente programático.

- Um trabalho considerável, mas que poderia se tornar repleto de ensinamentos, consistiria em estudar como o signo terrain surgiu no discurso da antropologia francesa: quando, em quais circunstâncias e por quais razões este signo começou a ser utilizado? O que revelam os contextos discursivos de suas primeiras ocorrências? Este trabalho permitiria colocar, no campo da língua, certo número de questôes cruciais referentes à origem, à história e ao estatuto epistemológico atual da antropologia francesa.

- Da mesma forma, seria interessante abordar, na perspectiva da linguagem, o problema das relaçóes que mantêm as diferentes tradiçóes antropológicas nacionais.

- Assim como boeuf e ochs náo devem ser confundidos (Benveniste,1939, referindo-se à Saussure, 1970, p.82), é preciso considerar o fato que terrain e field constituem dois conceitos distintos, vinculados a sistemas de signos diferentes, que não são, portanto, diretamente assimiláveis um ao outro ${ }^{23}$.

Para atermo-nos ao caso da língua inglesa, seria necessário verificar se o valor do signo field se organiza num campo semântico similar ao do signo terrain. Com restrições de análise detalhada, parece que a dimensão militar do signo está muito presente em inglês, como atestam as seguintes expressóes: field of batlle (campo de batalha), field-dressing (curativo de emergência), field-gun (canhão de campanha),

23. Deste ponto de vista, levaremos em consideração que as citaçôes de Condominas, Malinowski e Jones, reproduzidas neste artigo, são traduções em francês de frases inicialmente pronunciadas ou redigidas em inglês. NT. A mesma observaçáo vale para as traduçóes de terrain em português: campo/terreno. field-hospital (ambulância de divisão), fieldofficier (oficial superior). Aliás, no dicionário Harrap's encontramos: "field-work, s.l. Mil: obra de campanha, acampamento improvisado. 2. Trabalhos práticos, trabalhos de campo" (Mansion, 1974, p.F11).

No que se refere à questáo da apariçáo do signo field no discurso da antropologia britânica, Stocking destaca:

por ocasião de seu retorno, contudo, Haddon ativamente fez propaganda por mais "trabalho de campo" antropológico (um termo aparentemente derivado do discurso dos naturalistas, que Haddon parece ter introduzido no campo da antropologia Britânica) (1983, p. 80).

Por outro lado, seria necessário examinar como a referência à Geologia interveio nos discursos dos antropólogos anglo-saxôes. Já destacamos em outra ocasiáo, que Rivers apoiou-se nas metáforas geológicas (Pulman, 1986, p.128).

- Enfim, seria extremamente interessante ver como o signo campo é utilizado em disciplinas vizinhas da Antropologia (Pré-História, Arqueologia, Lingüística, Psicanálise etc), reformular sobre esta base o problema da relação entre antropologia e essas diferentes disciplinas.

Em relação à Lingüística, vimos que Saussure utiliza o signo para designar aquilo para o que, primeiro, a Lingüística deve voltar-se, a saber, a língua: "é necessário colocar-se primeiramente no terreno da língua e tomá-la como norma de todas as outras manifestaçôes da linguagem" (1965, p. 16). É precisamente o que procuramos fazer aqui em relação ao campo antropológico.

Do lado da Psicanálise, destacamos que, de acordo com Laplanche e Pontalis: 
$230 \mid$ Bertrand Pulman

A transferência é classicamente reconhecida como o campo em que se resolve a problemática de uma cura psicanalítica, sendo que sua instalação, suas modalidades, sua interpretação e sua resoluçáo a caracterizam (1967, p. 492).

A convergência léxica, sem dúvida, não é indiferente, na medida em que o campo antropológico pode ser visto como o lugar de uma situação transferencial (Devereux, 1967).

As regras da vida acadêmica fazem com que os antropólogos produzam um saber que toma essencialmente uma forma textual ${ }^{24}$. Assim, a transmissão da experiência vivida no campoCAMPO transita pela dupla mediação da língua e da escrita: sob campo .... a PÁGINA! ${ }^{25}$

Nos textos antropológicos, campo se assume como o lugar próprio do antropólogo: aquele que simboliza a particularidade do seu procedimento e exemplifica a veracidade do seu discurso. Todavia, este lugar não lhe pertence propriamente, pois nenhum indivíduo pode se apropriar da língua. Outros podem pretender usar o termo, como testemunha esta declaração: "o campo é por excelência o domínio do geólogo" (Pomerol e Blondeau, 1968).

Atualmente, o texto antropológico deve enfrentar um perigo: este lugar próprio ao antropólogo não pode se reificar em lugar-comum dos antropólogos. Trata-se de um problema de estilo, mas que toca no essencial! Um dicionário contemporâneo selecionou, para ilustrar a definição da expressão "lugar-comum", uma citação de Gide: "Somente nos entendemos sobre os lugares-comuns. Sem campo banal, a

24. Cf. Clifford e Marcus, 1986.

25. NT - Sous le terrain... la PAGE": a frase do original lembra um dos slogans mais famosos de maio de 1968, retomado de uma pichação: "Sous les pavés, la plage?' [Sob os paralelepípedos, a praia!] em referência aos paralelepípedos removidos para serem lançados ou amontoados em barricadas e que descobriam uma camada de areia que lembrava uma praia. sociedade não é mais possível" (Robert, 1986, p.1094) ${ }^{26}$. Isto poderia ser visto como um cuidado da própria língua?

Para um grupo definido de usuários, "o signo é, ao mesmo tempo, marca e ausência” (Ducrot e Todorov, 1973, p.128). Não deveríamos esquecer a complementaridade dessas duas dimensóes de campo.

\section{Referências bibliográficas}

ALLEGRE, Claude. L'Ecume de la Terre. Paris: Fayard, 1983.

ASSOCIATION FRANÇAISE DES ANTHROPOLOGUES. L'Ethnologue et son terrain. Textes rassemblés par Suzanne Lallemand et publiés in Bulletin de l'AEA. 29-30. Paris, 1987.

BATES, D.F.B. et KIRKALDY, J.F. La Geologie de Terrain. Paris: Nathan, 1977.

BENVENISTE, Émile. Problemas de Lingüistica Geral. São Paulo: Editora Nacional (Biblioteca Universitária Série 5; Letras e Lingüística, 8).Tradução de Maria da Glória Novak e Luiza Néri. 387p. 1976. [citação original: "Nature du signe linguistique", 1939. Repris in: Problèmes de Linguistique Géneral, vol.1. Paris: Gallimard Tel, 1966].

BIREMBAUT, Arthur. "La Géologie". In: Histoire de la Science. Sous la direction de M. Daumas. Paris: Gallimard (Encyclopédie de la Pléiade), 1957. p:10951127.

BRETON, André. "Main Première", Introduction à l'ouvrage de Karel Kupka: In: Un art à l'état brut: peitures et sculptures des aborigènes d'Australie. Lausanne: Éditions Clairefontaine, 1962. p:9-12.

BRONGNIART, Alexandre. Tableau des terrains qui composent l'écorce du globe - Essai sur la structure de la partie connue de la terre. Paris, 1829.

CLIFFORD, James. "Sobre a autoridade etnográfica". In: A experiência etnográfica: antropologia e literatura no século XX. Rio de Janeiro: Editora UFRJ. Tradução Patrícia Farias. 1998. p:17-62. [citação original: “De l'autorité en ethnographie”, L'ethnographie LXXIX (90-91), 1983. p:87-118

CLIFFORD, James and Marcus, George E. (Eds). Writing

26. Banal quer dizer: 1) que pertence ao senhor feudal e por extensão, à comuna; 2) comum e sem originalidade. 
POR UMA HISTÓRIA DA NOÇÃO DE CAMPO | 23 I

Culture: the poetics and politics of Ethnography. Berkeley: University of California Press, 1986. [Traduzido em espanhol: Retóricas de la Antropologia. Madrid: Jucár Universidad (Serie Antropologia), 1991].

CONDOMINAS, Georges. "Ethics and comfort. An ethnographer's view of his profession". Annual Report of the American Anthropological Association, 1972. p:1-15.

CORVISIER, André. Dictionnaire d'Art et d'Histoire Militaire. Paris: PUF, 1988.

DESNOYERS, Jules. Observations sur un ensemble de dépôts marins plus récents que les terrains tertiaires $d u$ bassin de la Seine. Paris, 1829.

DEVEREUX, George. From Anxiety to Method in the Behavioral Sciences. La Haye, Trad. franç.: Paris: Flammarion, 1980.

DUCROT, Oswald et Todorov, Tzvetan. Dicionário das Ciências da Linguagem. Lisboa: Publicaçôes D. Quixote (Colecção Informação e Cultura, 4). Traduçâo de: Antonio José Massano, José Afonso, Manuela Carrilho e Margarida Font. 445p. 1973. [citação original: Dictionnaire Encyclopédique des Sciences du Langage. Paris: Seuil (Collection Points Sciences Humaines n.110), 1972].

HAMELIN, Bruno et DUPRÉ, Bernard. "L'activité chimique de la Terre". In: La recherche, 19 (196), 1988. p. 164-173.

JONES, Ernest. "Psycho-Analysis and Anthropology". J.R. Anthrop. Inst. LIV:47-66. 1924. Trad.franç.in Psychanalyse, folklore, religion. Paris: Payot, 1973. p. 104-128.

LAPLANCHE, Jean et PONTALIS, J.B. Vocabulaire de la psychanalyse. Paris: PUF, 1967.

LEIRIS, Michel. L'Âge d'homme. Paris: Gallimard (Nouvelle édition Collection Folio n.435), 1939.

LÉVI-STRAUSS, Claude. "Lugar da Antropologia nas Ciências Sociais e Problemas Colocados por seu Ensino". In: LÉVI-STRAUSS, Claude. Antropologia Estrutural. Rio de Janeiro: Tempo Brasileiro (Biblioteca Tempo Universitário, 7). Tradução de Chaim Samuel Katz e Eginardo Pires. 1967. p. 385-424. [citação original: "Place de l'anthropologie dans les Sciences sociales et problèmes posés par son enseignement" (1954). Repris in: Anthropologie Structurale. Paris: Plon, 1958. p. 377-418].

LÉVI-STRAUSS, Claude. Tristes Trópicos. São Paulo: Companhia das Letras, Tradução de Rosa Freire D'Aguiar. 400p, 1996. [citação original: Tristes Tropiques. Paris: Plon, 1955].

MALINOWSKI, Bronislaw. "Myth in primitive psychology”, trad. franç. In: Trois essais sur la vie sociale des primitifs. Paris: Payot (PBP n.109), 1926. p. 97-154.
MANSION, J.E. Harrap's New Shorter French and English Dictionary, First published 1944. Reprinted with corrections and additions 1974. Part two EnglishFrench. London: Harrap; Paris: Bordas, 1974.

MARTINET, André. "Arbitraire Linguistique et Double Articulation". In: Cahiers Ferdinand de Saussure, 15, 1957. p. 105-116.

POMEROL, Charles et BLONDEAU, Alphonse. Initiation à la Géologie Pratique. Paris: N. Boubée et Ore, 1968.

PREVOST, Constant. Documents pour l'histoire des terrains tertiaires. Paris, 1827.

PREVOST, Constant. De la chronologie des terrains et $d u$ synchronisme des formations. Paris: Institut de France, 1845.

PREVOST, Constant. Annonce de la découverte d'un oiseau fossile de taille gigantesque trouvé à la partie inférieure de l'argile plastique des terrains parisiens. Paris, 1855.

PULMAN, Bertrand. "Aux origines du débat ethnologie psychanalyse W.H.R. Rivers (1864-1922)”. In: L'Homme, 100, XXVI(4), 1986. p. 119-142.

RABINOW, Paul. "Representations are Social Facts: Modernity and Postmodernity Anthropology". In: CLIFFORD, James and MARCUS,George E. (Eds). Writing Culture: the poetics and politics of Ethnography. Berkeley: University of California Press, 1986. [Traduzido em espanhol: Retóricas de la Antropologia. Madrid: Jucár Universidad (Serie Antropologia), 1991].

ROBERT, Paul. Dictionnaire Alphabétique et Analogique de la Langue Française, vol.6. Paris: Société du Noveau Littré, 1965.

ROBERT, Paul. Le Petit Robert, Nouvelle Édition Revue. Paris: Dictionnaires Le Robert, 1986.

SAUSSURE, Ferdinand de. "Notes antérieures à 1900", édité par R. Godel sous le titre "Notes inédites de F. de Saussure". In: Cahiers Ferdinand de Saussure, 12, 1954. p. 49-71.

SAUSSURE, Ferdinand de. Curso de Lingüistica Geral. São Paulo: Editora Cultrix, Tradução de Antônio Chelini, José Paulo Paes e Izidoro Blikstein. 279p. 1965. [citação original: Cours de Linguistique Générale (1906-1911). Nouvelle édition critique préparée par Tullio de Mauro. Paris: Payot, 1972].

STOCKING, George W. Jr. "The Ethnografer's Magic: Fieldwork in British Anthropology from Tylor to Malinowski”. In: STOCKING, George W. Jr. (org.) History of Anthropology, 1. Chicago: University of Wisconsin Press, 1983. p. 70-120. 
232 | Bertrand Pulman

traduzido de

PULMAN, Bertrand. Pour une histoire de la notion de terrain. In: Gradhiva: revue d'histoire et d'archives de l'anthropologie, Paris, no.5, p.21-30, 1988.

tradutora Wilma Marques Leitáo

Professora da Faculdade de Ciências Sociais/IFCH-UFPA

Doutora em Sociologia e Antropologia/IFCS-UFRJ

revisor Adriana de Oliveira Silva

Mestranda em Ciência Social (Antropologia Social)/USP

revisor Daniela do Amaral Alfonsi

Mestre em Ciência Social (Antropologia Social)/USP

tradutor Jayne Hunger Collevatti

Doutoranda em Ciência Social (Antropologia Social)/USP

tradutor Luísa Valentini

Mestranda em Ciência Social (Antropologia Social)/USP

Recebido em 10/09/2004

Aceito para publicação em 02/08/2007 